\title{
Study of Depth of Etching in Photo Chemical Machining by Coloured Phototool
}

\author{
Sumit S. Khajepawar, Guruprasad V. Badave, Shubham S. Bhosale, \\ Dnyanraj S. Telang, Nitin D. Misal
}

\begin{abstract}
The conventional machining deals with the removal of metal by direct contact between the tool and the work piece, which results into the formation of chips, debris, burr, etc. So, there is a huge scope for unconventional machining process. This paper focuses on study of Depth of etching in photochemical machining by using colored photo tool. The objective is to study the effect of different colored photo tools and achieve the stepped structure at micro level. This process is the bridge between 2D and 3D manufacturing processes. Initially the colored photo-tools are created; copper material was selected for experimentation. The control parameters selected were temperature, concentration and time. The concentration of etchant is $\mathbf{4 0 0}$ grams per liter. The temperature of the etchant is $\mathbf{5 0}$ degree Celsius and the time for etching is 300 seconds. The readings are taken by Digital Micro-meter.
\end{abstract}

Index Terms-Photo Chemical Machining, Photo tool, etching, stepped structure, photoresist

\section{INTRODUCTION}

Photochemical machining is one of the non-conventional machining processes that can produce complex shapes[1]. PCM is also known as photochemical milling or photo etching. It is chemical milling process used to fabricate sheet metal components using photoresist and etchant to remove material from the selected area by corrosion. Metal removal occurs due to the chemical reaction between the workpiece material and the chemical reagents like ferric chloride and cupric chloride [2,3]. Usually flat components from sheet metal are machined by the photochemical machining. The thickness of sheet material used varies from $0.01 \mathrm{~mm}$ to $1.5 \mathrm{~mm}$. For this study we have kept following parameters as constant; developing time as 120 seconds, concentration as 400 grams per liter and etching time as 300 seconds PCM combines chemical etching with micro-photography and photosensitive etchant.

Sumit S.Khajepawar, Mechanical Department, SVERI's COE, Pandharpur,India

Guruprasad V.Badave, Mechanical Department, SVERI's COE, Pandharpur,India

Shubham S. Bhosale, Mechanical Department, SVERI's COE,

Pandharpur,India

Dnyanraj S Telang, Mechanical Department, SVERI's COE,

Pandharpur,India

Nitin D. Misal,Principal,SVERI's COE (Polytechnic), Pandharpur,India
Today the cost of micro machining is expensive than macro machining. PCM offers economical and alternative way of other costlier processes like laser cutting. This method is relatively new. Though it is economical but relatively less popular process in the field of manufacturing. Owing to the development of micro fluidics and micro system technology over last 20 years, PCM has received greater attention. Most commonly used materials in the field of photochemical machining are copper, brass, stainless steel[2]. The major applications of this process are in the field of aerospace, biomedical, electronic parts and decorative items.
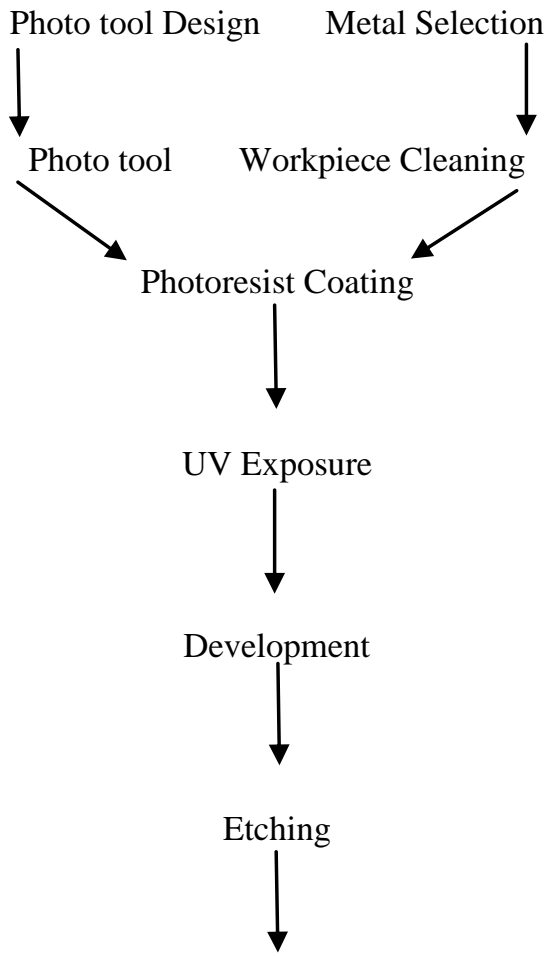

Photoresist Stripping<smiles>CC1([Tl])CCCCC1</smiles>

Finished Product

Fig.1: Steps in PCM

The Fig. 1 shows the basic procedure of the photochemical machining process. 
Cakir[4] and Saraf et al. [5]studied the effect of concentration, temperature, additives and etching time on responses like etch rate and surface finish for copper etching. Cakir [4] also studied the simultaneous regeneration of waste etchant.Atul R. Saraf and MudigondaSadaiahet al.[6] studied Magnetic field-assisted photochemical machining (MFAPCM) of SS316L and found that the etch rate is higher at higher temperature due to the higher rate of collusion between the atoms.N.D.Misalet al.[6] has studied Mathematical Modeling and Optimization of Photochemical Machining and investigated that the effects of process parameters settings on Photochemical machining of SS316L and Statistical regression analysis has been employed to develop mathematical models relating such process parameters as Temperature, Time and Concentration to the Undercut.

S.S. Wangikaretetal.[7] and Atul R Saraf [8] has studied Parametric Optimization for Photochemical Machining of Copperusing Overall Evaluation Criteria and obtained results by Taguchi's approach. Various studies have reported the parametric optimization of photochemical machining and fabricated the microchannels using photochemical machining [9-14].

\section{II.METHODOLOGY}

\subsection{Material selection: -}

The copper is the material used for this study, because it is more elastic after gold and aluminium. The size of specimen used is $30 \mathrm{~mm} \times 30 \mathrm{~mm} \times 1 \mathrm{~mm}(\mathrm{~W} \times \mathrm{L} \times \mathrm{T})$.

\subsection{Experimental procedure: -}

\section{Creating Phototool: -}

Photochemical machining process is carried out by using a photo tool. The photo tool is an AutoCAD drawing with detailed dimensions of the required shape which is then printed on a tress paper or transparent paper. Photo tools are shown in fig 2.
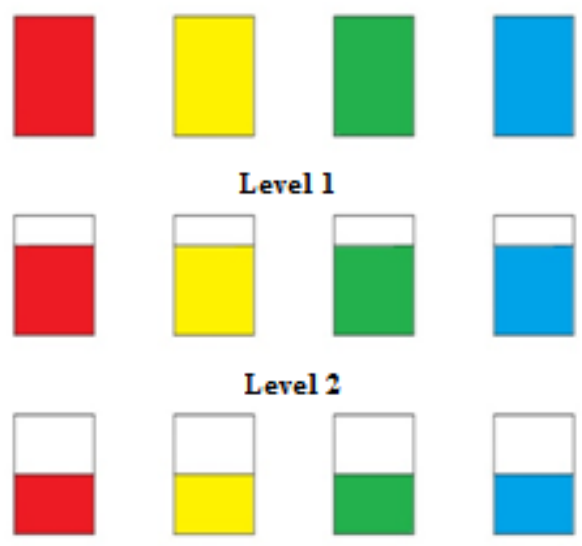

Level 3
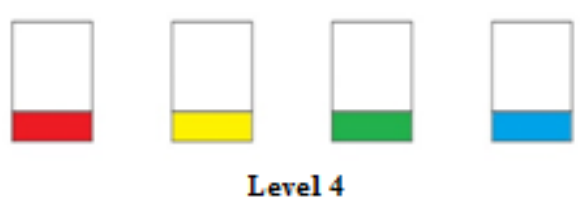

Fig 2. Photo tools

\section{Preparation of workpiece: -}

After preparing the photo tool the copper material is cut into required size. The first task is to clean the workpiece. The cleaning of the surface is done firstly by polishing the surface with a sand paper and then cleaning it by thinner (trichloroethylene or acetone). This step is done to make the surface of workpiece free from foreign particles, debris, dust, grease, oil and other contaminants. Because of polishing and cleaning with thinner it gets easier to have a good adhesion of photoresist with the metal surface.

\section{Coating of workpiece: -}

After cleaning the workpiece, a thin layer of photoresist is applied on the metal surface. There are two types of photoresists viz, positive photoresist and negative photoresist. For this study negative photoresist has taken. The characteristic of negative photoresist is that it hardens the area of metal from where the light is passed.Required chemicals for this process are shown in fig 3 .

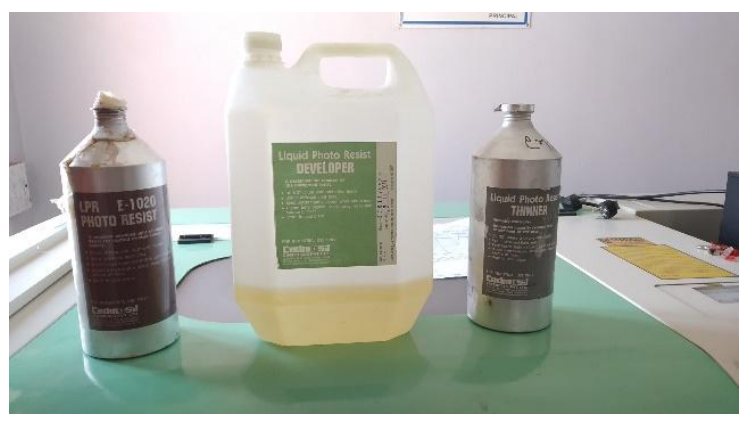

Fig 3.Chemicals required

\section{UV Exposure: -}

The generated photo tool is put on the coated workpiece and exposed to UV source for 120 seconds. The UV light used has the wavelength of $365 \mathrm{~nm}$ and light intensity of 18 $\mathrm{mW} / \mathrm{cm}^{2}$. The setup for UV exposure is as shown in fig 4.

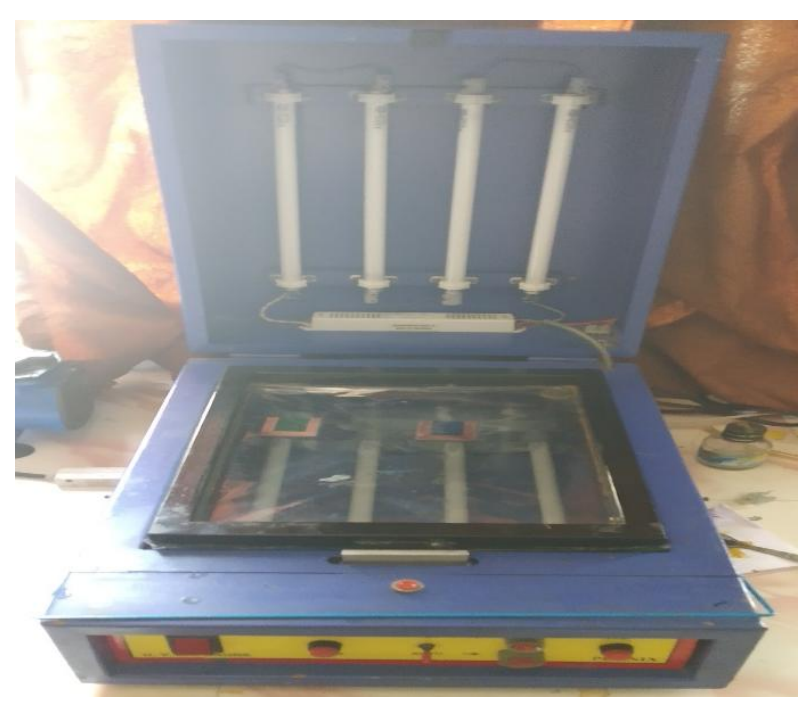

Fig 4. UV exposure Unit

Development Phase: - After UV exposure the specimen is held in the developer for 120 seconds, which results in the formation of impression on workpiece. After that specimen is washed with water

\section{Etching: -}

The final step of the machining is to put the developed metal workpiece into the etchant. The etchant is aqueous $\mathrm{FeCl}_{3}[15]$. The concentration of the etchant is 400 grams per liter and temperature of etchant is kept constant (50 degree Celsius). Etching is carried out for 300 seconds. At the end the specimen is cleaned by water and dried. The readings are taken by digital micro-meter. The etching unit is shown in fig 5 . 


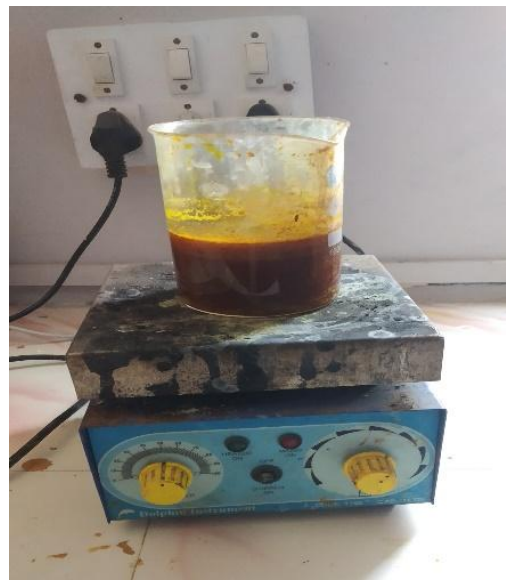

Fig 5. Etching unit

Formation of steps: -

Now, this process is repeated three times to achieve stepped structure at micro-level. For first time machining the whole area i.e. $30 \mathrm{~mm} \times 20 \mathrm{~mm}$, is covered in the process.

For second time machining, the $75 \%$ area $(22.5 \mathrm{~mm} \times 20 \mathrm{~mm})$ is covered in the process. This step will give us the first step at micro level. For third time machining, the $50 \%$ area $(15 \mathrm{~mm} \times 20 \mathrm{~mm})$ is covered in the process. This step will give us the second step at micro level. For fourth time machining $25 \%$ area $(7.5 \mathrm{mmx} 5 \mathrm{~mm})$ is covered in the process. This step will give the third step at micro level. So, stepped structure is achieved at micro-level as shown in fig 6 .

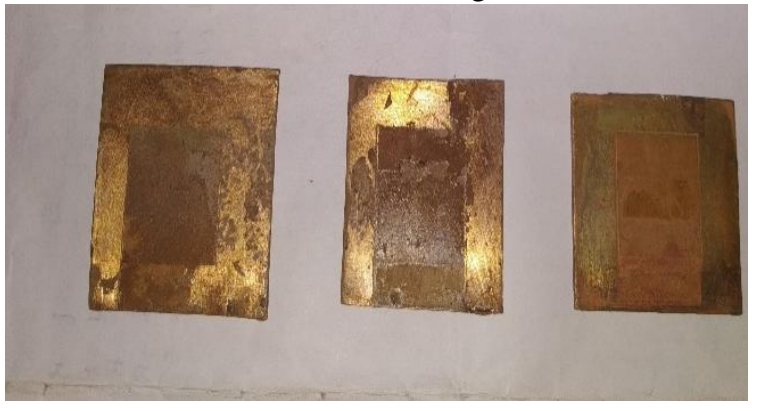

Fig 6.Finished component

\section{RESULT AND DISCUSSION}

After studying the process of photochemical machining by using coloured photo tool we get the following results for different colours having different wavelength as shown in Table 1 and graphical representation is shown in fig 7 .

Table 1

\begin{tabular}{|c|c|c|l|l|l|}
\hline $\begin{array}{c}\text { Level } \\
\text { Colour }\end{array}$ & $\begin{array}{l}\text { Plate } \\
\text { thickness } \\
(\mu \mathrm{m})\end{array}$ & 1 & 2 & 3 & 4 \\
\hline Black & 1030 & 980 & 958 & 936 & 914 \\
\hline Orange & 1035 & 987 & 968 & 941 & 928 \\
\hline Green & 1032 & 990 & 973 & 952 & 940 \\
\hline Blue & 1038 & 994 & 979 & 968 & 955 \\
\hline Violet & 1025 & 994 & 982 & 971 & 960 \\
\hline
\end{tabular}

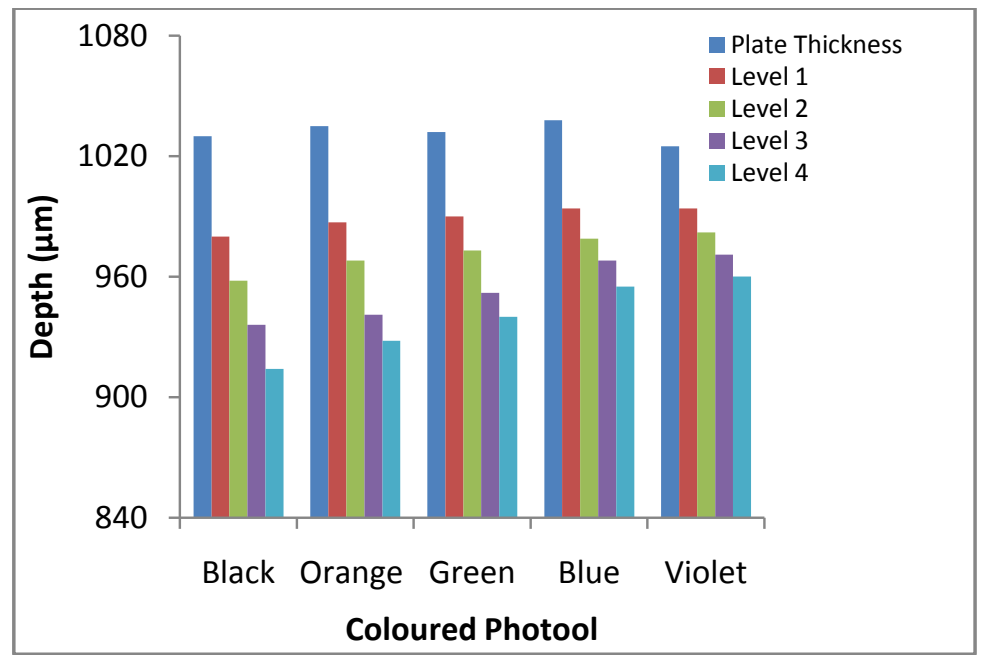

Fig 7. Effect of Coloured photo tool on depth of etch

$>\quad$ The negative photoresiist is used and UV light passes through the coloured photo tool, so the portion becomes hard from where maximum amount of light is passed and portion remains soft from where passing of light is less.

> Clear stepped structure is achieved for black coloured photo tool as compared to other colurs.

$>\quad$ Above chart shows the different depth of etching by different coloured photo tool.

$>\quad$ From experimental analysis, depth of eatching is directly proportional to the wavelengh of colour.

\section{CONCLUSION}

The present study investigates the depth of etching by different coloured photo-tools. As per this study, following conclusions were made.

1. In this study, the effects of process parameters were kept constant and the machining is studied by using different colours for photo-tool generation.

2. Depth of etching is directly proportional to wavelength of respective colour.

3. Highest depth of etching is achieved in black coloured photo-tool.

4. Lowest depth of etching is achieved in white coloured photo-tool.

\section{REFERENCES}

[1] S. S. Wangikar, P. P. Patowari, R. D. Misra, and N. D. Misal, "Photochemical Machining: A Less Explored Non-Conventional Machining Process", In Non-Conventional Machining in Modern Manufacturing Systems, pp. 188-201, 2018.

[2] Allen, D.M. Photochemical machining: from 'manufacturing's best kept secret' to a $\$ 6$ billion per annum, rapid manufacturing process. CIRP Annals - Manufacturing Technology 2004, 53 (2), 559-572. doi:10.1016/S0007-8506(07)60029-8

[3] Allen, D.M.; Almond, H.J.A. Characterisation of aqueous ferric chloride etchants used in industrial photochemical machining. Journal of Materials Processing Technology 2004, 149 (1-3), 238-245. doi:10.1016/j.jmatprotec.2004.02.044

[4] Cakir, O. Copper etching with cupric chloride and regeneration of waste etchant. Journal of Materials Processing Technology 2006, 175 (1-3), 63-68. doi:10.1016/j.jmatprotec.2005.04.024

[5] Saraf, A.R.; Sadaiah, M.; Devkare, S. Optimization of photochemical 
machining. Int Journal of Engineering Science and Technology 2011, 3 (9), 7108-7116.

[6] Atul R. Saraf \&MudigondaSadaiah (2016): Magnetic field-assisted photochemical machining (MFAPCM) of SS316L, Materials and Manufacturing Processes, DOI:10.1080/10426914.2016.1198014.

[7] S. S. Wangikar, P. P. Patowari, and R. D. Misra, "Parametric Optimization for Photochemical Machining of Copper Using Grey Relational Method", In Techno-Societal 2016, International Conference on Advanced Technologies for Societal Application, pp. 933-943, 2016

[8] Atul R. Saraf, M.Sadaiah,Santosh Devkare, 2011. Optimization of photochemical machining, Int. Journal of Engineering Science and Technology, Vol.3,No.9, 7108-7116.

[9] Wangikar, S. S., Patowari, P. K., \& Misra, R. D. (2017). Effect of process parameters and optimization for photochemical machining of brass and german silver. Materials and Manufacturing Processes, 32(15), 1747-1755.

[10] Wangikar, S. S., Patowari, P. K., \& Misra, R. D. (2018). Parametric optimization for photochemical machining of copper using overall evaluation criteria. Materials Today: Proceedings, 5(2), 4736-4742.

[11] Das, S. S., Tilekar, S. D., Wangikar, S. S., \& Patowari, P. K. (2017). Numerical and experimental study of passive fluids mixing in micro-channels of different configurations. Microsystem Technologies, 23(12), 5977-5988.

[12] Wangikar, S. S., Patowari, P. K., \& Misra, R. D. (2018). Numerical and experimental investigations on the performance of a serpentine microchannel with semicircular obstacles. Microsystem Technologies, 24:3307, 1-14.

[13] N. D. Misal, and M. Sadaiah, "Investigation on Surface Roughness of Inconel 718 in Photo chemical Machining", Advances in Materials Science and Engineering, 2017.

[14] N. D. Misal, A. R. Saraf, and M. Sadaiah, "Experimental investigation of surface topography in photo chemical machining of Inconel 718", Materials and Manufacturing Processes, vol. 32, no. 15, pp.1756-1763, 2017.

[15] Allen, David M., Almond, Heather J.A, 2004, "Characterization of aqueous ferric chloride etchants used in industrial photochemical machining", Journal of Materials Processing Technology, 149, $238-245$. 